\title{
Reseña. Casos ejemplares de comunicación: Comentarios y actividades para crecer hacia dentro, por Xavier Laborda Gil
}

2018, Editorial Horsori, Cuadernos para el análisis 50, 100 pp., 13.47€, ISBN: 978-84-947780-0-1, bttps://www.casadellibro.com/?gclid=CjwKCAjwtNf6BRAwEiwAkt6 UQqsNvWA9qTP49Z CtwsWbaRvJAf5EYY0jaw7lAkO4SaCO8evQMHLboCHRgOAvD BwE\& q=978-84-947780-0-1

Paulina Guajardo Figueroa

Universidad Autónoma de Barcelona

El discurso como herramienta vigorosa de la comunicación ha sido fuente de numerosos estudios por parte de científicos y pensadores que datan desde la Grecia antigua a la fecha. Sus orígenes se sustentan en la sofística con la práctica de la oratoria, pero se tangibiliza académicamente con la obra de Aristóteles y su teoría del lenguaje: La retórica. Esta disciplina no solo sistematizó el constructo fundamental de la comunicación que conocemos, sino que también estableció las técnicas persuasivas de utilización del lenguaje que siguen siendo utilizadas hasta el día de hoy: La oratoria, la lingüística y el análisis del discurso.

Xavier Laborda Gil, califica a la comunicación como una acción que nos permite crecer hacia afuera, esto es, tener la capacidad de repercutir en otras personas con nuestras líneas de pensamiento e ideologías para obtener su aprobación. Al final del libro, con un apartado de actividades sobre los casos, nos invita a crecer 
hacia adentro, a ser seres pensantes con ambición de conocimiento que nos permita construir discursos que sean significativos para el receptor.

El caso 1, la retórica en cuatro palabras, se analiza una pieza gráfica realizada por la escuela de idiomas modernos de la Universidad de Barcelona en 2015 y 2016. Son ocho palabras claves. La primeras cuatro "Imposible, desconexión, dependencia y timidez" aparecen tachadas, mientras que las restantes "oportunidades, comunicación, libertad y seguridad” figuran como antónimos no censurados que ostentan supremacía por sobre las palabras tachadas. Abajo, una frase que respalda los beneficios del aprendizaje y dominio de lenguas: "Los idiomas te dan más de lo que crees". El emparejamiento de estos ocho valores permite al autor estudiar en cuatro subapartados, la oposición semántica desde los principios retóricos del universo sofístico. Apoyándose en las escrituras sobre las polis de JeanPiere Vernant (1962), plantea que las oportunidades sustentadas en la palabra vienen a disipar lo imposible, pues en la ciudad griega se conformó una política democrática que privilegiaba la palabra por sobre otras herramientas de poder, favoreciendo la inclusión del ser humano en un entorno colectivo.

El régimen horizontal instaurado por la polis, está vinculado directamente con la comunicación, ya que, como plantea Jaqueline de Romilly (1988), la palabra, con su difusión pública, su efecto persuasivo y su proclamación como recurso de poder e igualdad crea una realidad que invalida la desconexión, reconociendo el legado del sofismo como fuente valiosa de teoría y práctica que contempla las bases de la democracia en la isonomía (igualdad de derechos civiles y políticos de los ciudadanos) e isegoría (derecho a cualquier ciudadano a ser escuchado). Emilio Lledó (2000) explica que estas bases son efectivas a medida que el derecho a la formación se aplica en la noción de la libertad de expresión desde la propiedad del pensamiento. El autor retrocede hacia el siglo IV para adentrarse en el poder de las palabras desde la invención de la prosa por Gorgias de Leontini y proclamarla como el producto inaugural de la retórica. Los efectos persuasivos de esta conforman la raíz del discurso público, y su praxis, en el contexto y estilo adecuados, inhibe la timidez y estimula la seguridad en el orador.

Finalmente, el autor lleva a cabo un razonamiento del anuncio, justificando la presencia de la retórica en un mensaje que apela al manejo de lenguas como una herramienta que disuelve la desigualdad comunicativa. Los valores oportunidades, comunicación, libertad y seguridad se presentan como un recordatorio de los elementos con que los sofistas construyeron el universo espiritual, y, por tanto, la formación integral de un individuo para su inclusión en la sociedad. 
El caso 2, La provocación de publicidad engañosa, trata de las campañas publicitarias emitidas durante el 2009 y 2010 por Endesa y Gas natural. Inicialmente, ambas organizaciones generaban servicios básicos diferentes, pero con los años lograron diversificar su producción y se convirtieron en competencia. El proceso de liberación del mercado energético decretado en 2009 autorizaba a las empresas a captar clientes y gestionar la comercialización, acción que estimuló el desarrollo publicitario. Laborda Gil profundiza en el análisis discursivo de los recursos argumentativos y ética dialógica de los anuncios de prensa y televisión de estas empresas, para sentenciar el uso de publicidad engañosa, utilizando dos perspectivas: 1) Teorías pragmáticas: Los actos del habla, el principio de cooperación y las propiedades del texto, y 2) Multimodalidad a través de cuatro instrumentos: los canales utilizados, variación discursiva de los mensajes, mecanismos implicados y la interacción de modalidades.

Ambas compañías poseen una estrategia expresiva multimodal donde existe una jerarquización descompensaba de información que destaca los descuentos como método de seducción, pero que a la vez camuflan la cláusula de mantenimiento que encadena a los clientes. Este tratamiento incompleto de la información presenta una praxis comunicativa deficiente habitual en la publicidad, dado que los consumidores suelen tener poco manejo de las características técnicas de la oferta, centrándose únicamente en el mensaje principal. El autor toma de referencia la obra de Vicent Salvador (2012) para referirse a la conciencia y su capacidad de interpretar correctamente mensajes que suelen formar parte de la reificación. El análisis del discurso sirve, entonces, para reconocer contenidos que tergiversan la realidad mediante la publicidad, herramienta que termina siendo solo un medio sobre el cual se debe cuestionar el actuar de las empresas promotoras carentes de honestidad.

En el caso 3, El anunciante de algo bueno y probibido, estudia el contenido de un pasquín repartido en una barriada, donde Marcos, un analfabeto funcional, publicitaba la venta de hachís. Laborda Gil analiza el prospecto en tres categorías: 1) Confianza en la lengua, 2) Cohesión infantil y adecuación deslenguada y 3) Mito cegador de la publicidad.

La primera categoría expresa la dificultad de lectura general, debido al incumplimiento de las propiedades del texto. Pese a la precariedad del anuncio, se da cuenta de una estructura coherente divida en cuatro párrafos que denota la priorización de información en un discurso que responde al qué, quién, dónde, cómo y cuánto. La segunda categoría, expone que la singularidad del anuncio radica en el 
incumplimiento de los patrones gráficos de la publicidad, puesto que sigue más el esbozo de una carta. Se analiza el escrito desde las propiedades comunicativas del texto: cohesión, coherencia y adecuación, para atribuir que la adecuación no es solo una propiedad formal, sino también material, pues depende de las pautas sociales. Por último, en la tercera categoría, Laborda Gil examina sobre la publicidad desde un escenario ilusorio. Marcos, a pesar de tener limitaciones graves como redactor, ve en la publicidad un poder extraordinario que coarta el temor a las consecuencias que su anuncio comprometía. Se controvierte la sobreexposición a los medios de comunicación social y la influencia que ejerce en las personas.

En el caso 3, Palabras de la tribu, Laborda Gil reseña obras de tres autores que tratan el discurso en diferentes ámbitos: La oratoria, la historia de la lingüista y el análisis del discurso. En primer lugar, David Crystal en El don de la gab: cómo funciona la elocuencia (2016) es el resultado de la unión de su valiosa actividad científica con temas de interés social donde enfatiza en la oratoria, la elocuencia, la narración, la retórica y el discurso público. El libro consta de tres componentes que inspiran a Crystal en su desarrollo: La filología para abordar la elocuencia en la comunicación pública británica, Manifestaciones comunicativas contemporáneas de oratoria política y sociocultural donde se identifica la persuasión multimodal y Sus reflexiones personales apoyadas en su trayectoria. Sus conocimientos orientados a la preponderancia de la elocuencia nos muestran que esta es una capacidad humana universal y que la comunicación está repleta de elementos persuasivos que cambian constantemente la naturaleza simbólica de la realidad, otorgándole protagonismo a la significación.

En segundo lugar, Laurent Binet, en La séptima función del lenguaje (2015), introduce una trama semiológica detectivesca que mezcla ficción con realidad donde el punto de partida es el atropello de Roland Barthes en 1980, luego de haberse reunido con François Mitterrand, un candidato presidencial francés de la época. La investigación del deceso de Barthes está a cargo de un policía y un profesor universitario experto en semiología, quienes en su círculo de sospechosos consideran a políticos e intelectuales históricos del estructuralismo y posestructuralismo, pues se presume que Barthes tenía un manuscrito que contenía la séptima función del lenguaje que le sucedía a las seis creadas por Roman Jakobson. Esta, le otorgaba el poder absoluto a quién la practicara, puesto que tenía la facultad de producir efectos inmediatos sobre la realidad. En las pistas, abundan elementos de la lingüística que proyectan una verdad de carácter universal: Existe un esfuerzo incansable del individuo por buscar la perfección, ser más influyente, y, por tanto, más poderoso. 
Por último, Amadeu Viana en Pasadizos (2015) trata la lingüística y su expansión de nuevas posibilidades. Laborda Gil aplaude el uso de aforismos, humor y fábulas con que Viana plasma su trayectoria académica dedicada a la corriente contextual y existencia lingüística. El autor preserva con un enfoque pragmático el modelo actual del discurso, donde la experiencia del hablante es indispensable para el estudio científico de la comunicación. La obra de Viana utiliza elementos como la persuasión, la significación, el pensamiento, el razonamiento, el ensueño y la verbalización, todos como producciones sociales y personales que proyectan el sentido común en la manifestación discursiva. Laborda Gil hace hincapié en un fragmento de Pasadizos donde asegura que la decadencia de las ciencias humanas se debe al despojo de la imaginación, y que una forma de reivindicación sería la alianza entre la filosofía y la filología, pues son dos polos complementarios del conocimiento en que integran la memoria crítica y perspectiva histórica.

El caso 5, Llamada personal del tribunal constitucional, se remonta a una grabación telefónica realizada el 2007 por la guardia civil, donde la presidenta del tribunal constitucional, Emilia Casas, conversa con María Dolores Martín, una abogada sospechosa de delito de sangre. Este acontecimiento gira en torno a tres panoramas: la conversación, los conflictos maritales de la sospechosa y la polémica pública que provocó el actuar de la magistrada, pues en efecto, comete la imprudencia de orientar a la abogada y, sin embargo, el Tribunal Supremo desestimó la acusación de asesoramiento ilegal, situación que causó un revuelo político entre diversos partidos y que Laborda Gil califica como un enfrentamiento teatral, excesivo y efímero, digno de la política contemporánea.

El autor estudia el comportamiento de la magistrada mediante dos instrumentos del análisis del discurso: 1) Petición de información en modalidad característica que utiliza recursos explícitos mediante preguntas y 2) Petición de información en modalidad no característica. De esta exploración, determina que el análisis lingüístico de la charla lleva a la misma deducción que el Tribunal Supremo. No obstante, Laborda Gil reconoce dos errores por parte de Casas: Presentar su cargo institucional y la imprudencia de llevar a cabo la entrevista sabiendo que todo magistrado tiene la prohibición de conocer casos que podrían llegar al Tribunal constitucional. En este caso, como bien concluye el autor, nos enfrentamos a un recordatorio de que la realidad se configura a partir de múltiples escenarios y la interpretación que los receptores le concedan a estos, especialmente en la política.

Esta obra, ideal para cualquier lector, presenta extraordinarios ejemplos sobre la comunicación y cómo sus diferentes discursos vehiculan la influencia de 
percepciones que emitimos y recibimos. La gran reflexión que nos entrega es que, crecer hacia adentro implica desarrollar un pensamiento crítico que estimule el razonamiento propio y consciente y aleje el constructo que sitúa a los seres humanos como seres reproductores de información.

\section{REFERENCIAS}

Binet, L. (2015). La séptima función del lenguaje. Barcelona: Seix Barral.

Crystal, D. (2016). The gift of the gab: how eloquence works. Reino Unido: Yale University Press. de Romilly, J. (1988). Los grandes sofistas de la Atenas de Pericles. Barcelona: Gredos.

Lledó, E. (2000). El surco del tiempo. Barcelona: Austral.

Vernant, Jean.-Piere. (1962). Los orígenes del pensamiento griego. México: UTEHA.

Viana, A. (2015). Pasadizos. Valencia: L'Eixam Edicions.

\section{Paulina Guajardo Figueroa}

Paulina Guajardo Figueroa es investigadora en el Laboratorio de Análisis Instrumental de la Comunicación (LAICOM). Socia fundadora de la Asociación Científica para la Evaluación y Medición de los Valores Humanos (AEVA). Profesora asociada en Universidad de Barcelona. Doctoranda en Comunicación Estratégica, Publicidad y Relaciones Públicas por la Universidad Autónoma de Barcelona.

paulina.guajardo@e-campus.uab.cat https://orcid.org/0000-0001-7628-3295

Guajardo Figueroa, P. (2021). Reseña. Casos ejemplares de comunicación: Comentarios y actividades para crecer hacia dentro, por Xavier Laborda Gil. Bellaterra Journal of Teaching \& Learning Language \& Literature, 14(3), e947. https://doi.org/10.5565/rev/jtl3.947 